\title{
artículos
}

\section{Clasificaciones alternativas: La national library of medicine classification}

\author{
Ma. Luisa Garza Ávalos, Inves- \\ tigadora del CUIB.
}

\section{Antecedentes}

En 1818, en dos habitaciones que contaban con una mesa, seis sillas y una caja para guardar documentos y libros, se estableció, en Washington, D.C., la Oficina del Cirujano General de la Armada. Su función básica era servir para solucionar las necesidades bibliográficas de los oficiales médicos militares. La oficina fue cobrando importancia con el crecimiento del país y al mismo tiempo, empezó a desarrollar una importante colección de libros y toda clase de documentos relacionados con la medicina y sus ciencias afines. ( 1 )

En 1840 la biblioteca que se generaba en dicha oficina tuvo su primer catálogo manuscrito de libros. La biblioteca cambió varias veces de nombre sin dejar de depender de la misma institución. En 1879 apareció la primera publicación del Index Medicus y un año después el Volumen No. 1 del Index Catalogue con lo que se inicia un programa oficial de publicaciones que prevalece hasta nuestros días.
Después de 120 años de estar auspiciada por las fuerzas armadas, en 1956 la biblioteca adoptó el estatuto y el nombre de la National Library of Medicine (NLM) dependiente del Servicio de salud Pública. (2)

En 1943, la biblioteca fue objeto de una evaluación de sus colecciones, patrocinada por la Fundación Rockefeller y auspiciada por la American Library Association. La evaluación fue hecha por Keyes D. Metcalf, Janet Doe, Thomas P. Fleming, Mary Louise Marshall, L. Quincey Mumford y Andrew D. Osborn.

El Informe del Estudio recomendó una reorganización administrativa, la contratación de bibliotecarios profesionales, la construcción de un nuevo edificio y lo más importante por lo que se refiere a este análisis: el desarrollo de un esquema de clasificación adecuado para la colección existente.

La primera edición de la clasificación apareció en 1951 con el título de Army Medical Library Classification. (3) En 1956 aparece con el nombre de National Library of Medicine Classification. Actualmente existe la cuarta edición publicada en 1978 y revisada en 1981. (4) 
Este es el resumen del análisis que he preparado como introducción general a la traducción de la NLMC, que actualmente reviso con la cooperación de Jorge Arellano Trejo. En el resumen elimino, entre otras cosas, los ejemplos que ilustran la introducción.

Estructura General

Relación con LC

La NLM es un sistema que se desarrolló en forma independiente, tomando como base y complemento al LC. La NLMC cubre medicina y ciencias afines; en sus esquema utiliza símbolos que la LC había reservado originalmente para expansión del sistema y que posteriormente decidió excluir permanentemente del mismo.

La NLMC no utiliza los esquemas de la LC para: anatomía humana (QM), microbiología (QR) y medicina ${ }^{\circledR}$, a las que asigna respectivamente los símbolos de las clases QS, QW Y W. En cambio, utiliza extensivamente los esquemas que LC ha desarrollado para: psicología (BF), sociología (HM), ciencias (qQP) y bibliografía (Z). En el índice de la NLMC se incluyen los símbolos de LC cuando se consideran pertinentes.

\section{Monografías}

Los símbolos QS-QZ, asignados a

las materias que NLMC denomina preclínicas, tienen el siguiente significado:

QS anatomía humana

QT fisiología

QU bioquímica

QV farmacología

QW bacteriología e inmunología

QX parasitología

QY patología clínica

QZ patología

La NLM utiliza los símbolos W-WZ para su esquema principal, que asigna para medicina y que tienen el significado siguiente:

W profesión médica

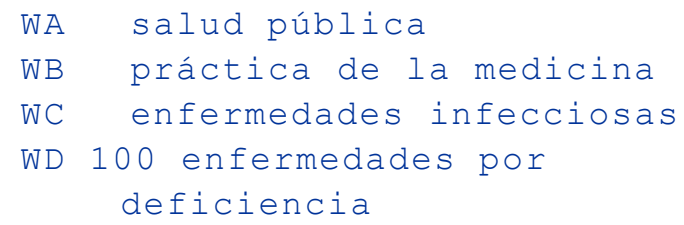

WD 200 enfermedades metabólicas

WD 300 enfermedades alérgicas

WD 400 enfermedades producidas

por animales ponzoñosos

WD 500 enfermedades producidas

por plantas venenosas

WD 600 enfermedades causadas por agentes físicos

WD 700 medicina aeronáutica y espacial

WE sistema óseo-muscular

WF sistema respiratorio

WG sistema cardiovascular

WH sistema hemático y linfático

WI sistema gastrointestinal

WJ sistema urogenital

WK sistema endócrino

WL sistema nervioso

WH psiquiatría

WN radiología

WO cirugía

WP ginecología

WR dermatología

WS pediatría

WT geriatría, enfermedades crónicas

WU odontología, cirugía bu$\mathrm{cal}$

WV otorrinolaringología

WW oftalmología

WX hospitales

WY enfermería

WZ historia de la medicina

Clases y subclases

De los materiales que se manejan como monografías la NLMC establece una clasificación por materia, separa por forma las publicaciones periódicas que, además divide en grandes categorías que más adelante, en la descripción de series, se observan.

Cada una de las clases principales se compone de subclases como LC. 
Las clases y algunas subclases, tienen un formato similar en lo que se refiere a los 33 primeros números; como sociedades, trabajos generales, colecciones, ensayos, discursos, conferencias, historia, diccionarios, enciclopedias, etcétera, que representan determinantes de forma, con pequeñas variantes derivadas de la naturaleza del material.

La NLMC utiliza subdivisiones alfabéticas con la forma de números de Cutter para el arreglo de tópicos dentro de números de clasificación que ha empleado extensivamente tanto para trabajos generales como específicos.

La NLM utiliza, generalmente, las tablas de tres cifras de cutter Sanborn (5), con algunas modificaciones en caso de áreas muy saturadas.

La Tabla Geográfica (G)

Para las subdivisiones geográficas, la NLMC se remite a la tabla G que consiste en una división del mundo en diez grandes regiones, a quienes le han sido asignadas para su identificación, en forma arbitraria, una letra en la siguiente forma:

$\begin{array}{ll}\text { A. } & \text { Estados Unidos } \\ \text { D. } & \text { América } \\ \text { F. } & \text { Gran Bretaña } \\ \text { G. } & \text { Europa } \\ \text { H. } & \text { Árica } \\ \text { J. } & \text { Asia } \\ \text { K. } & \text { Australia } \\ \text { L. } & \text { Islas del Pacífico } \\ \text { M. } & \text { Internacional } \\ \text { P. } & \text { Regiones polares } \\ \text { Cada } & \text { región se divide: }\end{array}$

a) con números adicionales para el caso del gobierno federal norteamericano $y$,

b) con letras y números para el resto de los casos.

Series

La NLMC se adhiere a la definición de las publicaciones seriadas como aquellas que se publican en partes sucesivas por término indefinido, como los periódicos, revistas, actas y memorias de congresos; anuarios, series numeradas y otros tipos de continuaciones. (6)

La NLMC divide las publicaciones seriadas en las siguientes categorías:

1. Biomedicina

2. Ciencia de la información y referencia general

3. Congresos

4. Hospitales

5. Informes estadísticos o administrativos

6. Números especiales de forma

7. İndices y bibliografías

Las politicas que utiliza la NLM para el arreglo de publicaciones seriadas es la siguiente:

1. Todas las series, independientemente del título que puede ser individual o corporativo, se les da entrada bajo el nombre que tienen en el momento de su registro por primera vez en la biblioteca. 2.El número tipográfico se asigna con base en la primer entrada del catálogo, en caso de no contarse con la serie completa, no necesariamente tiene que representar el primer título de la publicación. Debido a la gran cantidad de material que se recibe en esta área las publicaciones seriadas en NLMC no utilizan el sistema Cutter Sanborn, que consideran impráctico para sus fines. La fórmula que se usa es la siguiente:

1. Utiliza las primeras dos letras de la entrada, exceptuando artículos, por ejemplo:

ME, para medicina.

2. Con el fin de evitar una notación demasiado larga, se utilizan los números del 101 al 999 con cada combinación de dos letras, a menos que la biblioteca tenga más de 500 entradas bajo el mismo par de le- 
tras combinadas, en ese caso se usan desde 2 hasta 5 números (1199999) dependiendo del número de entradas involucradas. (7)

3.Los números se asignan en la misma forma que las de Cutter, es decir secuencialmente, pudiéndose expandir en forma decimal.

\section{Bibliografías}

La NLM clasifica las bibliografías de medicina con una $\mathrm{z}$ que precede al número de NLMC. El término bibliografía se utiliza en el sentido amplio que permite extenderlo a catálogos de bibliotecas y editores, hemerografías e índices. Cuando estos no están relacionados con la materia médica, se clasifican con el esquema Z de LC. Material bibliográfico del Siglo $\underline{\mathrm{XIX}}$

El material bibliográfico del SigloXIX, en el sistema de clasificación de NLM, comprende publicaciones de 1801 a 1913.

Se concreta a monografías que están ordenadas por materia en forma simplificada, que se reduce a la combinación de dos o tres letras seguidas de uno o dos números continuando con la misma secuencia asignada a las ciencias preclínicas, (QS, QT, QU, etc.) se presenta como excepción el uso de una sola letra (W) para medicina general, así como una sola letra con un numeral para W1: series, publicaciones periódicas, W2: documentos, W3: congresos: W4: disertaciones. W4A: disertaciones norteamericanas y W6: panfletos. Libros publicados antes de 1801 Los trabajos publicados antes de 1801 integran una parte especial del esquema, no son clasificados por materia; en lugar de eso, están arreglados en forma alfabética por autor bajo el número de clasificación correspondiente al siglo durante el cual fueron escritos.

En la clase WZ, Historia de la medicina, aparece una tabla basada en el American Imprints Inventory for USA que se denomina Americana y consiste en un listado de los estados y algunas ciudades principales, acompañadas de una fecha determinada que va desde 1820 hasta 1890 .

Los encabezamientos para el esquema principal son dados en forma breve. Debe interpretarse en forma amplia abarcando las regiones anatómicas conectadas con el sistema fisiológico, los problemas específicos relacionados con aquel y los asuntos relacionados a éste tópico. (8) Dentro del esquema la división por órganos tiene prioridad. Los trabajos relativos a una enfermedad en particular se clasifican con la enfermedad, la cual se relaciona con el órgano o región afectada, haciendo caso omiso del énfasis que se le podría dar a la dieta, fármaco o cualquier otra forma especial de terapia.

Los trabajos que tengan varios temas y que podrían caber en diferentes áreas de clasificación, se clasificarán en el tema que sea tratado más extensamente, y si no se presenta el caso se clasificarán por el primer tema que aparez$\mathrm{ca}$.

\section{Bibliografía}

1. DOROThy M. SHULLIAN [y] Frank B. Rogers, "The National Library of Medicine : 1", Library Quarterly (XXVIII, 1, Jan, 1958) pp. 1-4. 
2. Ibidem y "National Library of Medicine : II" (XXVIII, 2, Apr., 1958) p. 118.

3. Library Research and Technical Services (Vol. 1 : Summer, 1957) pp. 139-140.

4. National Library of Medicine Classification; a scheme for the shelf arrangement of books in the field of medicine and its related sciences (4 ed.; DHEW Publication No. 78 - 1535; Bethesda, Maryland : NLM, 1978) x1iii, 390 p.

5. CHARLES ARMI CUTTER, C.A. Cutter's alphabetic order table, altered and fitted with three figures by Kate E. Sanborn. (Boston: Library Boreau, 189 [s.p.] mimeogr.)

6. MARY CATHERINE ARICK. "Subclassification and book numbers of documents and official publications" in: The use of Library of congress classification: Proceedings of the Institute [...] sponsered by the American Library association, Research and Technical Services Division, Cataloging and Classification Section, New York, July 7-9, 1966. Editado por Richard H. Schimmelpfeng [y] Donald Cook (Chicago: ALA, 1975, c 1968) p. 155.

7. KANCHANA, SOPHANODORN. "Problems of the National Library of Medicine Classification for serials" Library Resources and Technical Services (XV, No. 4 Fall, $1971)$ p. 453.

8. FRANK B., Rogers. "Problems of medical subject cataloging" Bull. Med. Lib. Assn. (56: oct. 1968) p. 361 . 